\title{
Encefalitis herpética neonatal: dos gemelas, dos casos
}

\author{
Natalia Conca M., Yenis Labraña C., Mariana Bercovich W., \\ Guillermo Cienfuegos S. y M. Elena Santolaya De P.
}

\section{Neonatal herpes simplex encephalitis: two twins, two cases}

Herpes simplex encephalitis is an infrequent infection with high mortality and morbidity. Antiviral therapies decrease mortality but long term sequelae are still high, so early diagnosis is important for opportune treatment. We present a pair of twins with central nervous system herpes simplex infection during the first month of life. Both twins presented non-specific symptoms and consulted with 48 hours apart needing intensive care admission, the first one for noninvasive mechanical ventilation and the second for hemodynamic support. Diagnosis was made by cerebrospinal fluid PCR, in the first twin at day 9 of disease and in the second at admission. Both twins were treated with acyclovir, but only the second one at the beginning of her illness. Initial study with electroencephalogram and magnetic resonance was normal and cerebrospinal fluid on day 18 of treatment was negative for herpes simplex virus DNA detection in both patients.

Key words: Herpes simplex, encephalitis, newborn.

Palabras clave: Herpes simplex, encefalitis, recién nacido.

\section{Introducción}

L

a infección por virus herpes simplex (VHS) del recién nacido es una entidad poco frecuente (1:3.000-1:20.000 recién nacidos vivos'1), pero que condiciona alta mortalidad y secuelas neurológicas. A su vez, la infección intrauterina es una complicación inusual de la infección por este virus y casi siempre con resultados fatales para el niño ${ }^{2,3}$.

Las infecciones genitales por VHS tipo 1 (VHS 1) y tipo 2 (VHS 2) han ido en aumento en el mundo, siendo una de las enfermedades de transmisión sexual más frecuentes. Si bien clásicamente se ha descrito a VHS 1 como causante de enfermedad oro-labial y a VHS 2 de la genital, la aparición de VHS 1 como causa de lesiones genitales ha ido aumentando en los últimos años, llegando a representar 30 a $50 \%$ de los herpes genitales ${ }^{4}$.

La probabilidad de adquirir esta enfermedad en la etapa adulta es directamente proporcional a la cantidad de parejas sexuales y el traspaso de VHS al feto y al recién nacido requiere de la replicación activa del virus en el tracto genital. Lo anterior ocurre en la primoinfección y el riesgo es algo menor en las recurrencias ${ }^{1}$. Sesenta a $80 \%$ de las madres que tienen hijos con infección neonatal por VHS no tienen historia previa de herpes genital y las recurrencias en $85 \%$ son asintomáticas ${ }^{5}$. Esto hace difícil el ubicar a las posibles mujeres embarazadas cursando con infección activa y realizar profilaxis adecuada o cesárea electiva, que disminuya el traspaso del virus ${ }^{1}$.

El espectro clínico de la infección por VHS en el recién nacido agrupa tres síndromes clínicos que se superponen entre sí: la forma diseminada, que da cuenta de $25 \%$ de los casos, la infección mucocutánea o de piel-ojo-boca y el compromiso de sistema nervioso central (SNC) $(60 \%-75 \%)^{1}$.

El compromiso del SNC por VHS en recién nacidos presenta algunos retos diagnósticos: los síntomas de la enfermedad son inespecíficos y similares a los de un niño cursando con una infección bacteriana grave, el estudio del líquido cefalorraquídeo (LCR) realizado en etapas precoces de la enfermedad puede resultar normal o con pocas células inflamatorias, e incluso la realización de reacción de polimerasa en cadena (RPC) en LCR puede ser negativa pues este examen tiene una sensibilidad sólo cercana al 70\% durante los primeros tres días del cuadro clínico ${ }^{1,4}$.

Un evidente progreso ha sido el uso de las terapias antivirales como aciclovir en dosis altas (60 mg/k/día), que ha logrado disminuir la mortalidad de la encefalitis neonatal por VHS desde 50 a $4 \%{ }^{6}$. A pesar de lo anterior, las secuelas neurológicas a largo plazo, como parálisis cerebral, siguen siendo altas (30-70\%); de allí la gran trascendencia que tiene sospechar esta patología e iniciar su tratamiento precozmente.

\section{Casos clínicos}

Se presenta el caso de dos gemelas con encefalitis herpética iniciada en ambas durante el segundo mes de
Universidad de Chile, Santiago, Chile. Facultad de Medicina Programa de Formación en Infectología Pediátrica (NCM, YLC). Departamento de Pediatría (MESdeP).

Hospital Luis Calvo Mackenna Unidad de Lactantes (MBW). Unidad de Recién Nacidos (GCS). Unidad de Infectología (MESdeP).

Recibido: 24 de junio de 2010 Aceptado: 23 de febrero de 2011

Correspondencia a: Natalia Conca Minaeff nconca@yahoo.com 
vida. Hijas de una madre aparentemente sana, de 16 años, con embarazo controlado en una unidad de alto riesgo obstétrico, por ser una gestación gemelar en una madre adolescente y presentar pre-eclampsia, nacieron de un embarazo monocorial biamniótico. Parto de pretérmino (35 semanas de gestación), vaginal eutócico, con cinco horas de membranas rotas. Sin antecedentes maternos de lesiones genitales ni fiebre en el preparto.

La gemela II, con peso de nacimiento de 2.415 gr, adecuado para la edad gestacional, APGAR 9 al minuto y 9 a los 5 minutos, fue llevada al servicio de urgencia, a los 33 días de vida, por decaimiento, rechazo alimentario, palidez y extremidades frías, con 24 horas de evolución. La madre refería haber observado en ella algunos episodios de mirada fija y sialorrea, no asociados a movimientos anormales. Interrogada dirigidamente, relató que la niña no había presentado fiebre, aunque sí rechazaba la lactancia materna en el día de la consulta. Al ingresar, se apreciaba en buenas condiciones generales, con signos vitales normales, sin lesiones de piel ni mucosas ni otros hallazgos al examen físico pero, por la sospecha de un episodio convulsivo se le ingresó a la unidad de recién nacidos. Durante las primeras horas de hospitalización presentó polipnea e hipotonía de extremidades, junto con al menos ocho episodios de pausas respiratorias asociadas a desaturación, requiriendo su conexión a ventilación mecánica (VM) no invasora. Dentro de los exámenes de ingreso destacaban leucocitos de $11.100 / \mathrm{mm}^{3}$, hematocrito 36\%, hemoglobina 12 gr.\%, proteína $\mathrm{C}$ reactiva (PCR) $0 \mathrm{mg} / \mathrm{L}$, natremia de $120 \mathrm{mg} / \mathrm{dl}$, sin otras alteraciones de electrolitos o del perfil bioquímico. Una punción lumbar, que resultó traumática, dio los siguientes resultados: glucorraquia $39 \mathrm{mg} / \mathrm{dL}$ (glicemia concomitante $99 \mathrm{mg} /$ dl), proteinorraquia $181 \mathrm{mg} / \mathrm{dl}$, eritrocitos: $32.000 / \mathrm{mm}^{3}$ (eritrocitos frescos), leucocitos $200 / \mathrm{mm}^{3}$, $49 \%$ polimorfonucleares (PMN). En la tinción de Gram directa no se visualizaron bacterias.

Se diagnosticó un síndrome convulsivo y, dado la punción lumbar traumática y de difícil interpretación, considerando una probable meningitis bacteriana aguda, con un aumento relativo de leucocitos en el LCR en relación a los eritrocitos e hipoglucorraquia, se inició tratamiento empírico con cefotaxima (150 mg/kg día) y ampicilina (200 mg/k/día), y se corrigió la hiponatremia. El electroencefalograma (EEG) fue informado con discreta lentitud basal simétrica sin actividad epiléptica. La ecografía cerebral resultó normal.

La paciente evolucionó con estabilidad clínica, alimentándose bien, afebril, sin irritabilidad ni alteraciones del examen físico general y segmentario, sin lesiones de piel ni mucosas. Al tercer día de evolución se desconectó de VM, sin requerimientos adicionales de oxigeno. Los controles de hemograma, PCR, perfil bioquímico y electrolitos plasmáticos fueron normales. Los cultivos bacteriológicos de sangre, orina y LCR fueron negativos. Se suspendió entonces, la terapia antibacteriana.

$\mathrm{Al} 5^{\circ}$ día de hospitalización, dado sus buenas condiciones, se trasladó a sala de cuidados básicos para continuar el estudio del síndrome convulsivo, posiblemente secundario a la hiponatremia detectada al ingreso.

A las 48 horas de hospitalizarse la gemela II, la madre consultó nuevamente en la unidad de emergencia, esta vez por la gemela I. Como antecedente, esta gemela había nacido con APGAR 9-9, permaneciendo hospitalizada por ictericia neonatal que sólo requirió fototerapia.

Aproximadamente tres horas antes de ser ingresada, la madre le notó decaída, pálida y con rechazo alimentario. A su ingreso estaba irritable, decaída, con hipoperfusión periférica, con taquicardia y febril $\left(38,5{ }^{\circ} \mathrm{C}\right.$ axilar). Al examen físico presentaba una piel de aspecto reticulado, pálida, y sin alteraciones al examen segmentario. Recibió inicialmente solución fisiológica ( $\mathrm{NaCl}$ 9\%o) 20 cc/kg en bolo, con lo que se estabilizó hemodinámicamente. Una punción lumbar dio salida a LCR claro cuyo análisis citoquímico fue: glucorraquia: 48 mg/dl (glicemia concomitante $95 \mathrm{mg} / \mathrm{dl}$ ), proteinorraquia $129 \mathrm{mg} / \mathrm{dl}$, leucocitos 305/ $\mathrm{mm}^{3}$ (47\% PMN), sin eritrocitos. En la tinción de Gram directa no se visualizaron bacterias. El hemograma mostraba hematocrito 27,4\%, hemoglobina 9,5 gr\%, leucocitos $11.600 / \mathrm{mm}^{3}$ (84\% linfocitos) y plaquetas 431.000/ $\mathrm{mm}^{3}$. PCR: $0 \mathrm{mg} / \mathrm{L}$, sin otras alteraciones en el estudio bioquímico básico. Se inició su reanimación con volumen y tratamiento antimicrobiano con cefotaxima más ampicilina y aciclovir en dosis de 60 mg/k/día y se le transfundió eritrocitos por caída del hematocrito a 21,6\% y hemoglobina de 7,6 g/dl. No requirió apoyo ventilatorio ni de aminas vasoactivas. En su tercer día de evolución se le realizó una segunda punción lumbar, que mostró una glucorraquia de $44 \mathrm{mg} / \mathrm{dl}$, proteinorraquia $79 \mathrm{mg} /$ dl, eritrocitos $40 / \mathrm{mm}^{3}$, leucocitos $20 / \mathrm{mm}^{3}$ (sin fórmula), tomándose además muestra de LCR para estudio de VHS por RPC tiempo real en Light Cycler y RPC para enterovirus. Se mantuvo el tratamiento con cefotaxima, ampicilina y aciclovir en espera de los análisis de laboratorio. La paciente continuó evolucionando favorablemente, afebril, sin compromiso hemodinámico, y al séptimo día de evolución llegó la RPC positiva en LCR, para VHS (la escasez de material genético impidió su tipificación). La RPC para enterovirus fue negativa. En los cultivos de sangre y LCR no hubo desarrollo bacteriano. Se suspendió entonces, la terapia antibacteriana.

Tomando en cuenta los antecedentes del segundo caso, se reevaluó a ambas gemelas.

La gemela I se encontraba en tratamiento con aciclovir desde su ingreso y estable, sin nuevas manifestaciones neurológicas ni compromiso hemodinámica, y afebril a partir del tercer día de hospitalización. Se le realizó tomografía axial computada (TAC) cerebral, y posterior- 
mente resonancia magnética (RM) de cerebro y EEG que resultaron normales. El día 18 de tratamiento con aciclovir se realizó control del LCR con análisis citoquímico normal y RPC negativa para VHS 1 y 2, completando 21 días de tratamiento antiviral.

El mismo día que se informó la RPC para VHS en la gemela I se reevaluó a la gemela II que se encontraba en su noveno día de evolución, sin tratamiento antiviral, asintomática, afebril, alimentándose normalmente. Tomando en cuenta los antecedentes de la gemela I, se le realizó una nueva punción lumbar y se inició aciclovir (60mg/k/ día). El nuevo LCR (no traumático), tenía aspecto transparente, glucorraquia 50mg/dL, proteinorraquia $82 \mathrm{mg} / \mathrm{dL}$, eritrocitos $100 / \mathrm{mm}^{3}$, leucocitos $5 / \mathrm{mm}^{3}$ (sin fórmula), la RPC para VHS dio resultado positivo. Un nuevo EEG y RM de cerebro resultaron normales. Se mantuvo estable, de buen aspecto, sin complicaciones. Un control de LCR a los 18 días de tratamiento con aciclovir resultó normal con RPC para VHS negativa, completando 21 días de tratamiento antiviral, sin complicaciones.

A ambas gemelas se les realizó serología para virus de hepatitis B, VDRL y estudio de virus de inmunodeficiencia humana, con resultados negativos.

Un resumen de la evolución clínica y del LCR en ambas gemelas se aprecia en la Tabla 1 .

Las niñas fueron enviadas a su domicilio en buenas condiciones, alimentándose espontáneamente, con buen incremento de peso y sin deterioro neurológico aparente al momento del alta. Al año de edad, ambas presentaban desarrollo psicomotor normal.

\section{Discusión}

En estos dos casos se conjugaron varios hechos que retardaron la sospecha de infección herpética: ausencia de lesiones genitales atribuibles a VHS en la madre durante la gestación, aún considerando que era controlada en una unidad de alto riesgo obstétrico; el inicio tardío de los síntomas -en promedio la presentación de la infección connatal por VHS es alrededor del día 1912-ambas gemelas debutaron con síntomas bordeando los 30 días post-parto; ninguna de las dos gemelas presentó exantema vesicular, el que se ha descrito con una frecuencia mayor al $60 \%$ en los casos de enfermedad del SNC y en 58\% de los casos la enfermedad diseminada ${ }^{4}$; la ausencia de lesiones oro-labiales o panadizo herpético en otros miembros de la familia, antecedente que está presente en $~ 10 \%$ de los casos de infección herpética neonatal.

Sin embargo, la presentación clínica en ambas fue concordante con las descripciones en la literatura científica para un recién nacido: un especial neurotropismo del VHS que se traduce en rechazo alimentario, letargia, convulsiones, compromiso de conciencia ${ }^{7,8}$; y compro-
Tabla 1. Evolución clínica y del LCR en dos gemelas con encefalitis herpética

\begin{tabular}{|c|c|c|}
\hline & Gemela 2 & Gemela 1 \\
\hline Edad de hospitalización & 33 días & 35 días \\
\hline Síntomas de ingreso & $\begin{array}{l}\text { Rechazo alimentos, palidez, decai- } \\
\text { miento, mirada fija }\end{array}$ & $\begin{array}{l}\text { Rechazo alimentación, palidez, } \\
\text { decaimiento }\end{array}$ \\
\hline Evolución clínica inicial & $\begin{array}{l}\text { Polipnea, hipotonía, pausas respira- } \\
\text { torias. Conexión a VM }\end{array}$ & $\begin{array}{l}\text { Febril, irritable, piel reticulada, } \\
\text { hipoperfusión tisular }\end{array}$ \\
\hline $\begin{array}{l}\text { LCR } 1 \\
\text { (día de hospitalización) }\end{array}$ & $1^{\circ}$ & $1^{\circ}$ \\
\hline $\begin{array}{l}\text { LCR } 1 \\
\text { Análisis citoquímico }\end{array}$ & $\begin{array}{l}\text { Glucosa } 39 \mathrm{mg} / \mathrm{dL} \\
\text { (glicemia } 99 \mathrm{mg} / \mathrm{dL} \text { ) } \\
\text { Proteínas } 181 \mathrm{mg} / \mathrm{dL} \\
\text { Leucocitos } 200 / \mathrm{mm}^{3} \text { (49\% PMN) } \\
\text { Eritrocitos: } 32.000 / \mathrm{mm}^{3}\end{array}$ & $\begin{array}{l}\text { Glucosa: } 48 \mathrm{mg} / \mathrm{dL} \\
\text { (glicemia } 95 \mathrm{mg} / \mathrm{dL} \text { ) } \\
\text { Proteínas } 129 \mathrm{mg} / \mathrm{dL} \\
\text { Leucocitos } 305 / \mathrm{mm}^{3} \text { (47\% PMN) } \\
\text { Eritrocitos } 0\end{array}$ \\
\hline $\begin{array}{l}\text { LCR } 1 \\
\text { Análisis microbiológico }\end{array}$ & $\begin{array}{l}\text { Gram: } \sin \text { M.O. } \\
\text { Cultivo (-) }\end{array}$ & $\begin{array}{l}\text { Gram: } \sin \text { M.O. } \\
\text { Cultivo (-) }\end{array}$ \\
\hline $\begin{array}{l}\text { Otros exámenes de in- } \\
\text { greso }\end{array}$ & $\begin{array}{l}\text { PCR } 0 \mathrm{mg} / \mathrm{dL} \\
\text { Natremia } 120 \mathrm{mg} / \mathrm{L}\end{array}$ & PCR: $0 \mathrm{mg} / \mathrm{L}$ \\
\hline Evolución clínica & $\begin{array}{l}\text { Afebril, estabilidad clínica, ausencia } \\
\text { de lesiones muco-cutáneas. Retiro } \\
\text { V.M. a las } 72 \text { horas. ¿Hiponatre- } \\
\text { mia? EEG y R.M. normales }\end{array}$ & $\begin{array}{l}\text { Estabilidad clínica, afebril, sin lesio- } \\
\text { nes muco-cutáneas. TAC cerebral, } \\
\text { EEG y RM normales }\end{array}$ \\
\hline $\begin{array}{l}\text { LCR } 2 \\
\text { (día de hospitalización) }\end{array}$ & $9^{\circ}$ & $3^{\circ}$ \\
\hline $\begin{array}{l}\text { LCR } 2 \\
\text { Análisis citoquímico }\end{array}$ & $\begin{array}{l}\text { Glucosa } 50 \mathrm{mg} / \mathrm{dL} \text { (glicemia n.e.) } \\
\text { Proteínas } 82 \mathrm{mg} / \mathrm{dL} \\
\text { Leucocitos } 5 / \mathrm{mm}^{3} \text { (sin fórmula) } \\
\text { Eritrocitos } 100 / \mathrm{mm}^{3}\end{array}$ & $\begin{array}{l}\text { Glucosa } 44 \text { mg/dL (glicemia n.e.) } \\
\text { Proteínas } 79 \mathrm{mg} / \mathrm{dL} \\
\text { Leucocitos } 20 / \mathrm{mm}^{3} \text { (sin fórmula) } \\
\text { Eritrocitos } 40 / \mathrm{mm}^{3}\end{array}$ \\
\hline Análisis microbiológico & $\begin{array}{l}\text { Gram: } \sin \text { M.O. } \\
\text { Cultivo (-) } \\
\text { RPC cualitativa: VHS (+) }\end{array}$ & $\begin{array}{l}\text { Gram: } \sin \text { M.O. } \\
\text { Cultivo (-) } \\
\text { RPC cualitativa: VHS (+) }\end{array}$ \\
\hline $\begin{array}{l}\text { Inicio de aciclovir } \\
\text { (Día de hospitalización) }\end{array}$ & $9^{\circ}$ & $1^{\circ}$ \\
\hline $\begin{array}{l}\text { Aciclovir (ACV) } \\
\text { Duración de tratamiento }\end{array}$ & 21 días & 21 días \\
\hline $\begin{array}{l}\text { LCR } 3 \\
\text { Día de terapia con ACV }\end{array}$ & $18^{\circ}$ & $18^{\circ}$ \\
\hline $\begin{array}{l}\text { LCR } 3 \\
\text { Análisis microbiológico }\end{array}$ & $\operatorname{RPC}(-)$ & $\operatorname{RPC}(-)$ \\
\hline
\end{tabular}

miso hemodinámico como fuera observado en la gemela I, el que se ha descrito preferentemente en las formas sistémicas de enfermedad neonatal. En estas pacientes no se documentó la diseminación hematógena del virus, podría haberse evaluado mediante RPC en sangre, lo que no fue efectuado.

Otra dificultad diagnóstica para reconocer la encefalitis herpética es que el análisis citoquímico del LCR puede ser normal o tener mínimas anormalidades si la punción lumbar es realizada muy precozmente. El LCR de la gemela II tenía gran cantidad de eritrocitos -posiblemente fue una punción lumbar traumática-; en ella, la relación 
leucocitos/eritrocitos, comparada con el hemograma, sólo explicaba un exceso de 67 leucocitos $/ \mathrm{mm}^{3}$ en LCR, lo que fue inicialmente interpretado como una meningitis bacteriana aguda. Se decidió repetir la punción lumbar al $9^{\circ}$ día de evolución, y se realizó RPC para VHS de este LCR (no se disponía de alícuota remanente del primer LCR) con resultado positivo. El estándar de oro para el diagnostico de encefalitis por VHS es la RPC en LCR $\mathrm{y}$, aunque el rendimiento los primeros tres días es de aproximadamente $70 \%$, aumenta hasta cerca de $100 \%$ si la muestra de LCR se obtiene entre el tercer y quinto día de evolución ${ }^{9}$. La RPC realizada en LCR al noveno día resultó positiva para VHS aunque la cantidad de ADN no fue suficiente para tipificarlo Por el contrario, el LCR de la gemela I tenía mayor carácter inflamatorio y la ausencia de bacterias en la tinción de Gram orientó hacia una posible etiología viral desde un inicio.

La gemela II, aunque no recibió aciclovir durante los primeros nueve días de internación, mantuvo, sorprendentemente, su buen estado general y no experimentó deterioro neurológico. El EEG inicial sólo mostró lentitud y una RM de cerebro efectuada luego de iniciar la terapia con aciclovir fue normal. La gemela I, que inició tratamiento con aciclovir al primer día de síntomas, tuvo EEG y RM de cerebro normales. Usualmente los pacientes presentan alteraciones en la TAC cerebral que van desde compromiso bilateral con zonas de baja densidad en el (los) lóbulo(s) temporal(es), a hemorragias, necrosis y tardíamente calcificaciones ${ }^{10}$. La RM tiene mayor sensibilidad para detectar las lesiones precoces producidas por VHS y aún así, en estas pacientes el estudio fue negativo. En los EEG no apareció actividad eléctrica anormal ni focal que pudieran orientar a la etiología.

En ambas pacientes se efectuó control del LCR antes de completar 21 días de aciclovir, según es la recomendación actual ${ }^{5}$, con RPC para VHS, en esta oportunidad, negativa en las dos.

Las gemelas fueron dadas de alta con su madre sin mayores complicaciones. A un año de seguimiento neurológico, el desarrollo psicomotor de ellas era completamente normal. La evolución de las pacientes fue inesperadamente benigna. La mortalidad de la encefalitis neonatal por VHS alcanza a 50\% y aumenta hasta $85 \%$ en la forma de herpes diseminado; según DW Kimberlin y cols, es mejor el pronóstico neurológico y vital de la encefalitis neonatal si el tipo causal es VHS-1, con una probabilidad de secuelas al año de vida, de 25 vs 67,5\% en los sobrevivientes de infección por VHS-2 y una letalidad de 0 vs $15 \%$, respectivamente ${ }^{11}$, dato que permite especular que la infección en las gemelas pudiera haber sido causada por VHS-1.

Aciclovir, en dosis de $60 \mathrm{mg} / \mathrm{kg} /$ día ha logrado reducir la letalidad de la encefalitis a $\sim 4 \%^{1}$. Las secuelas, sin embargo, siguen siendo inconvenientemente altas ( 30\% a los 12 meses de vida), a pesar del tratamiento con aciclovir ${ }^{1}$. Será necesario un seguimiento a largo plazo para evaluar la aparición de secuelas neurológicas aún no detectadas en estas dos pacientes.

Aproximadamente la mitad de los pacientes con infección diseminada presentará recurrencias cutáneas, situación en la que se ha intentado una terapia de supresión con aciclovir; su beneficio está en discusión ${ }^{5}$. Nuestras pacientes no presentaron lesiones cutáneas durante la hospitalización ni en el mes posterior al egreso.

\section{Resumen}

La encefalitis herpética en una infección poco frecuente, pero que condiciona alta morbilidad y mortalidad. Las terapias antivirales han logrado disminuir la mortalidad pero no las secuelas a largo plazo que siguen siendo altas, por lo que el énfasis está puesto en la precocidad del diagnóstico, en aras de implementar un tratamiento oportuno. Se presenta el caso de dos gemelas con encefalitis causada por virus herpes simplex durante el primer mes de vida. Ambas gemelas presentaron síntomas inespecíficos al mes de vida y consultaron con 48 horas de diferencia, necesitando cuidados intensivos, la primera por requerimientos de ventilación mecánica no invasora y la segunda por inestabilidad hemodinámica. El diagnostico fue realizado por RPC cualitativa en LCR positivo para VHS, en la primera gemela el día 9 de síntomas y en la segunda al momento de su consulta. Ambas gemelas recibieron aciclovir, pero sólo la segunda precozmente, desde el inicio de los síntomas. El estudio inicial en ambas, incluyendo EEG y RM, resultó normal y el LCR del día 18 de tratamiento no presentaba ADN de VHS en ambas pacientes.

\section{Referencias}

1.- Kimberlin D W. Neonatal herpes simplex infection. Clin Microbiol Rev 2004; 17 (1): 1-13.

2.- Jayaram, PM, Wake CR. A rare case of absent corpus callosum with severe ventriculomegaly due to congenital herpes simplex infection. J Obstetr Gynaecol 2010; 30 (3): 316.
3.- Lee A, Barr-Zeev N, Walker S P, Permezel M. In utero herpes simplex encephalitis. Obstetr Gynecol 2003; 102 (5 Pt 2): 1197-9.

4.- Kimberlin D W. Herpes simplex virus infections in the newborn. Seminars Perinatol 2007; 31 (1): 19-25.

5.- American Academy of Pediatrics, Herpes simplex. In Pickering LK, Baker KJ, Kimberlin
DW, Long SS, eds. Red Book 2009 Report of the Committee on Infectious Diseases $28^{\text {th }}$ ed. Elk Grove Village, IL: American Academy of Pediatrics 2009: 363-73.

6.- Jones C A, Walker K, Badawi N. Antiviral agents for treatment of herpes simplex virus infection in neonates. Cochrane Database Syst Rev 2009; (3): CD004206.

7.- Strelow LI, Leib DA. Role of the virion host 
shutoff (VHS) of herpes simplex virus type 1 in latency and pathogenesis. J Virol 1995; 69: 6779-86.

8.- David A T, Baghian A, Foster T P, Chouljenko V N, Kousoulas K G, et al. The herpes simplex virus type 1 (HSV-1) glycoprotein $\mathrm{K}(\mathrm{gK})$ is essential for viral corneal spread and neuroinvasiveness. Curr Eye Res 2008; 33: 455-
67.

9.- Lakeman F D, Whitley R J. Diagnosis of herpes simplex encephalitis: application of polymerase chain reaction to cerebrospinal fluid from brain-biopsied patients and correlation with disease. J Infect Dis 1995; 171: 857-63.

10.- Benator R M, Magill H L, Gerald B,
Igarashi M, Fitch S J. Herpes simplex encephalitis: CT findings in the neonate and the young infants. Amer J Neuroradiol 1985; 6 (4): 539-43.

11.- Kimberlin D W, Lyn C Y, Jacobs R F, Powell D A, Frenkel L M, Gruber WC, et al. Natural history of neonatal herpes simplex virus infections in the acyclovir era. Pediatrics 2001; 108: 223-9. 